\title{
An Online Multi-Eatry Management System
}

\author{
Ikono Rhoda \\ Senior Lecturer, \\ Department of \\ Computer Science and \\ Engineering \\ Obafemi Awolowo, \\ University, Ile-Ife \\ Osun State, Nigeria
}

\author{
Yange Simon \\ Lecturer, \\ Mathematics/Statistics/C \\ omputer \\ Science Dept, University \\ of \\ Agriculture, Makurdi, \\ Nigeria
}

\author{
Ishaya Gambo \\ Lecturer I, Department of \\ Computer Science and \\ Engineering \\ Obafemi Awolowo, \\ University, Ile-Ife \\ Osun State, Nigeria
}

\author{
Temitayo Oyegoke \\ Assistant Lecturer, \\ Department of \\ Computer Science and \\ Engineering \\ Obafemi Awolowo, \\ University, lle-Ife \\ Osun State, Nigeria
}

\begin{abstract}
Over the years eatries have attracted massive patronage following the trend by which people no longer have time to cook before making it to their respective places of work which has brought much concern because of the massive turn up at the eatry premises leading to crowdedness and insufficient space to accommodate customers and also the fact that customers having not attended to on time, as a result forced to wait longer than they should. This research built an application to incorporate ease, accuracy and comfort with the view of addressing the above stated problem. In order to achieve the aim of this paper, investigation of the existing system was done via extensive review of literature, interview and observation. The design was done using unified modeling language and entity relationship diagram. And it was implemented using Java programming language, and MySQL as the database management system. The system used Titto Gate, Mr Biggs, Steam Fast, and Ostrich Bakery all in Makurdi metropolis as case studies. The result shows that most processes in the manual system are not recorded, staffs spend too much time correcting mistakes instead of attending to customers, lack of tally in inventory and discrepancies towards customers. These issues are all eliminated in the online automated system. This system minimized repetitive work done by the system administrator and staff as it is very common in the manual system; minimized the level of crowdedness at the eatry premises, thereby maintaining steady patronage; increased quality of service and customer satisfaction; make dinning a social tool; ensured accountability and error free handling of customer information and lots more.
\end{abstract}

\section{Keywords}

Eatry, restaurant, hotel, online, automated, manual

\section{INTRODUCTION}

Various kinds of Eatries serve various purposes, hence they fall into several industrial classifications based upon menu style, preparation methods and pricing. Conventionally, eatries also called restaurants refers only to places that provide tables and chairs where one can sit down to eat a meal typically served by a waiter. In search of restaurant [1] experience, argues that all restaurants can be categorized according to a set of social parameters defined as polar opposites, higher or low, cheap or dear, familiar or exotic, formal or informal and so forth. Restaurant will be relatively high or low in style and price, familiar or exotic in the cuisine it offers to different kinds of customers.

As technology advances in every ramification, Eatries and restaurant are not an exception. That is, in the traditional way by which Eatries/restaurants are run when a customer visits the premises to makes orders and wait for the ordered meal, he or she may not be served promptly considering the number of persons that might have been waiting before his or her arrival; these can lead to dissatisfaction of the customer. Over the years eatries/restaurants attracted massive patronage following the trend by which people no longer have time to cook before making it to their respective places of work. These has brought much concern because of the massive turn up at the eatry premises leading to crowdedness and insufficient space to accommodate customers and also the fact that customers having not attended to on time, as a result forced to wait longer than they should.

Other challenges faced by the system includes; inactive staff, error due to inattentiveness of the waiter in taking orders, excess billing to customers and complaints such as customers been served food which they did not order for and so on. It is of great importance everything sustainable should go through advancement. In science and technology, the desire for improvement and advancement cannot be over emphasized; hence almost everyday activity is gradually going through technological influences with the aim of saving time, energy and resources. Thus, a need to build an application to incorporate ease, accuracy and comfort is felt.

Therefore, our desire in this research is to build an online eatry management system that will address most of the aforementioned problems faced by the existing system. It would require customers to go online to place orders or reservation for food and also ensure accountability and error free handling of customer informations. Here, we try to see how eatry management can be automated such that customers would not have to visit the eatry premises but at their convenient time and places, make order for food and as well make reservation when necessary, and their orders are delivered to them.

\section{REVIEW OF RELATED WORKS}

The negative financial impact on the hospitality industries are caused by harsh economic conditions [2]. The behavioural pattern of consumers have been change for several reasons, 
including high levels of unemployment, a deep recession, and over all fear of what the future holds. Innkeepers and restaurateurs will need to look at various strategic vehicles to build and to recover customers' confidence. The eatry industry need to take a practical stand in realizing high-tech advances. While trying to build levels of service quality and quest loyalty, [3] and [4] opined that some eatries business base comes from repeat customers and tapping into their needs through the use of information can be instrumental in building loyalty and gaining competitive advantage [5].

Eatries are continually competing for workers, sites and more recently information about clients. As most people are internet users, there is huge volume of information that is being captured via the web server logs [6], and extracting this information will help the Hotel and restaurant industry build competitive advantage in a troubled economy. The ability of an organization to take advantage of external environmental influences will help such firms sustain and grow in economically challenging times [7]. [5] opines that establishments need to structure their thinking about how clients reason and act. By achieving a customer-centered focus, organizations will be able to highlight their strength and opportunities for improvement. Information regarding customers will continue to have a big impact on the future of the industry.

\subsection{The Environments for Eatries}

There are two basic environments for eatries: external and internal. From an external perspective, there are two distinct environments, the broad environment and the task or firm environment [8][9]. The broad environment is based on factors such as societal trends, technological advances political and legal trends, economic factors and other major industry innovations; while the task or firm environment looks at factors such as customers, computation, government agencies, suppliers, and financial intermediaries. Lastly, the internal environment focuses on factors within the firm such as management financial and human [10]. In this paper, our focus is on the broad environment for eatries.

\subsection{The Broad Environment for Eatries}

Analyzing the broad environment discovered more opportunities for eatry organizations. Eatry managers need to be consider these factors and how they affect in the industry. Trends in both the society and technology should be considered as critical points of interest by industry executives. From a societal perspective, eatry companies need to look at influences such as emerging areas, attitudes demography shifts and new facts [7][8].

A common example of societal trends is the explosion of social networking. This has traversed across several demographic barriers extending from Baby Boomers to the millennial. They have additionally been massive effect on the hotel and restaurant industry Bloggers have lunched sites commenting about experiences that they have had and have made recommendations regarding the hotel or restaurant. Savvy industry consecutives understand the impact of these societal trends and focus efforts on establishing methodologies that can incorporate appropriate strategies to take advantage of these trends [11].
Technological advances in this area concentrate on the invention of product, procedures, or services and how this development can affect the hospitality industry [8][12]. For example, online booking and reservation have grown exponentially over the years [13]. The ability for industry captains to identify the implications of this technical advances and develop strategies to take advantage of it is a critical component of strategy development [14].

The systems being developed and implemented by eatries are have ultimately increased the level of service quality and client satisfaction. As it was viewed in researches conducted in the hotel industry, the primary motivation is the improvement of the level of service to the guests [6][15][16][17].

\subsection{Online Food Ordering}

Online food ordering systems are web-based applications with interactive menus allowing clients to place orders for food. It is very similar to online shops, many of which allow clients to create accounts with them so as to make frequent ordering convenient [18].

Currently, many eatries offer the technology to place an order using web-based technologies, and many restaurants offer a special incentive if the order is made via such applications. With these applications, it is very easy for such eatries to reach a larger market which is technology friendly; for instance, many people nowadays have smart devices that aid them in doing things at ease [19].

The merits are enormous for clients that who participate in online ordering. First, a client can order at will when they have time to. Also, the client is able to customized their order they way they like it without errors in communication between the customers and the person taking the order. In addition to client advantages, the eatry is able to take more orders with less staff. The eatry does not need a waiter or hostess to be on the phone to take the order, the order can go straight to the kitchen [19].

\section{METHODOLOGY}

In order to achieve the aim of this paper, investigation of the existing system was done via extensive review of literature, interview and observation. The design was done using unified modeling language and entity relationship diagram. And it was implemented using Java as the programming language for the software development, and MySQL as the database management system (DBMS) which ensures that computer records are kept up to date and made available on demand to those who need them for planning and operational purposes.

The four eatries in the Makurdi metropolis were considered during the development: Mr Biggs, Steam Fast, Ostrich and Tito Gate. This system offers a wide selection of features to improve control of business and saves time spent and resources on inventory, purchasing and accounting.

\subsection{Analysis of the Existing System}

This analysis covers the problems and challenges faced by the existing system mention above in chapter one of its scope, these challenges are inherent in the manual way of ordering for food which has call for concern for a new 
approach in the system, to enhance dining experience of customers and reduce errors captured in the existing system.

The main ideal here is that, the system is manual, as a result inherited with challenges such as lack of tally in inventory, sales going unrecorded, staff spending too much time chasing mistakes instead of attending to customers. These and other snafus suggest that its time that a new approach be adopted by stepping up to a computerized food ordering system to ensure efficiency and accountability.

\subsection{Design of the Proposed System}

Data flow Diagram: A data flow diagram (DFD) is a graphical representation of the "flow" of data through an information system modeling. A DFD is often used as a preliminary step to create an over view of the system, which can later be elaborated. The data flow diagram is shown in Fig 1.

Activity Diagram: Activity diagram is a graphical representation of workflow of stepwise activities and actions with support for choice iteration and con currency. The activity diagram for this system is shown in Fig 2 .

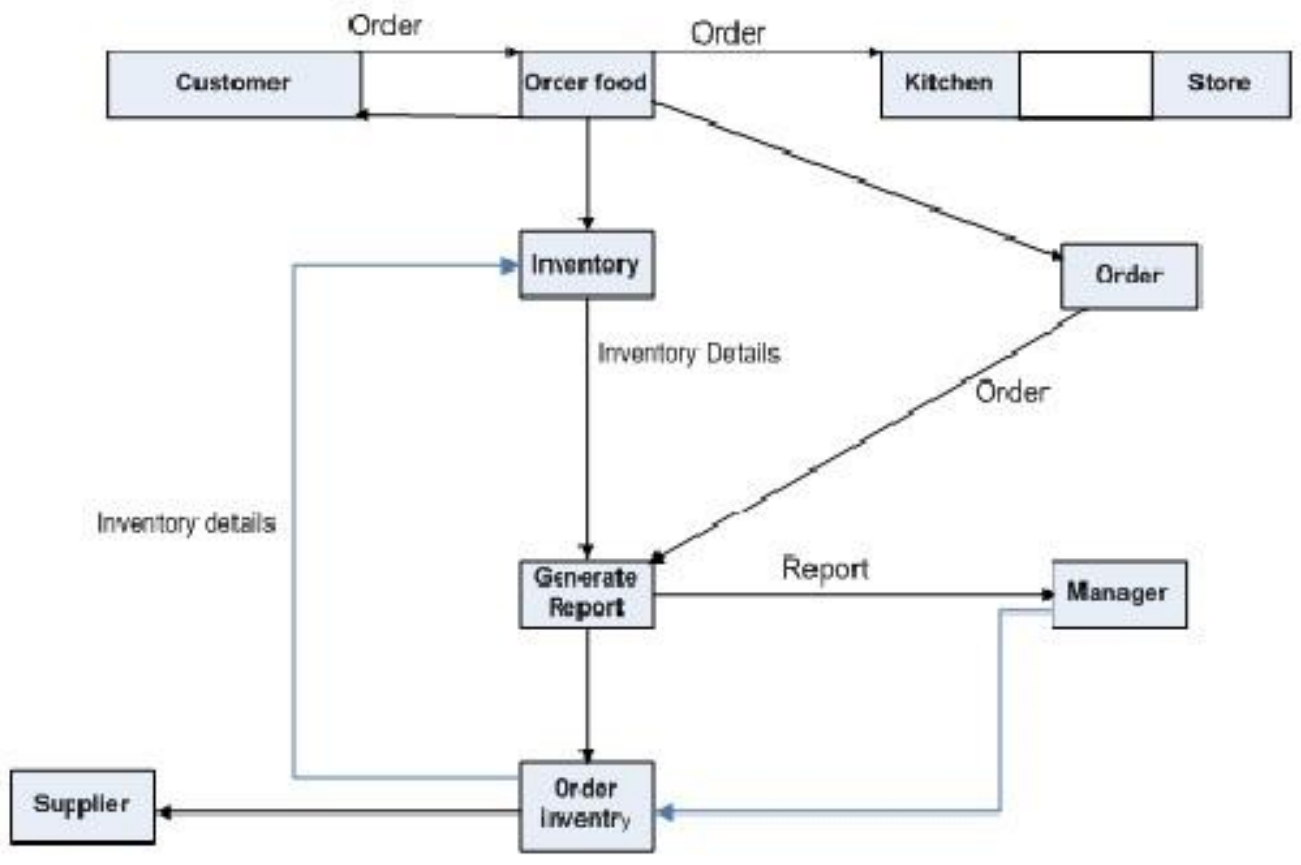

Fig 1: Data Flow Diagram

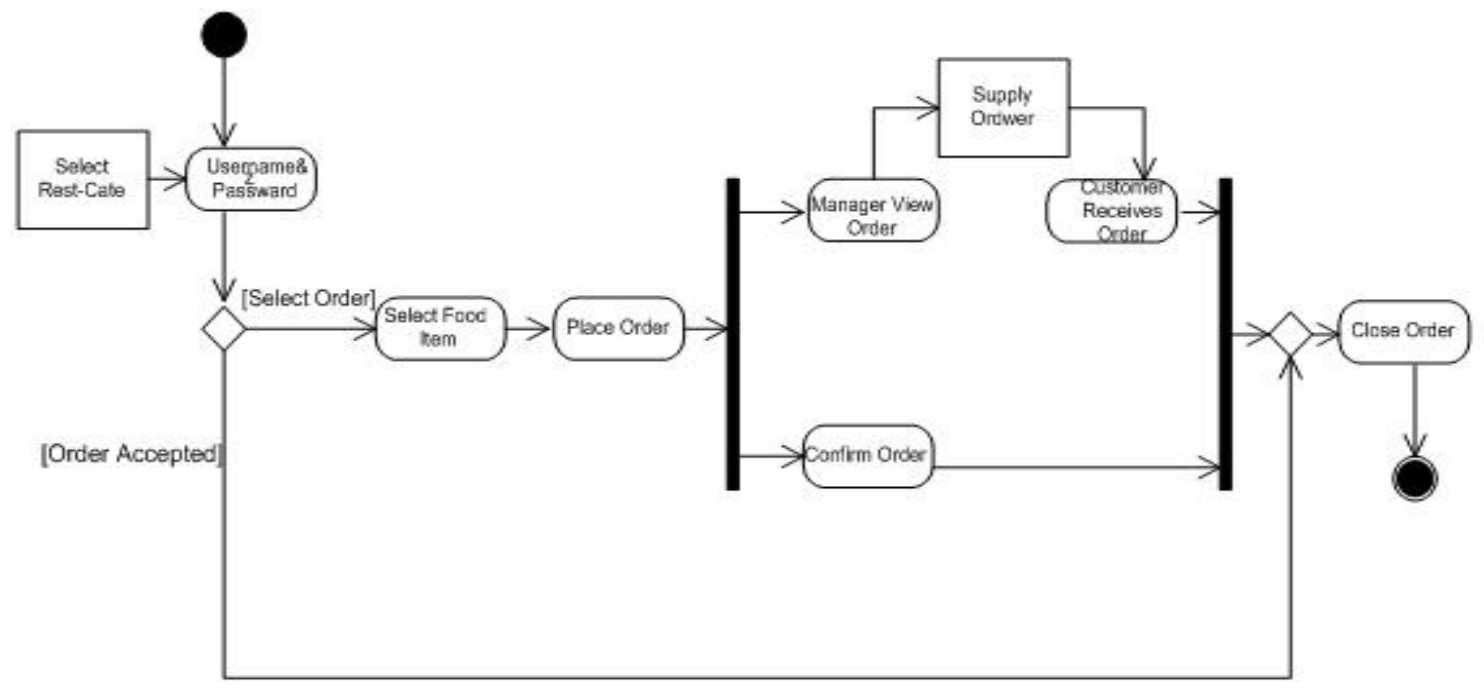

Fig 2: Activity Diagram 
Sequence Diagram: A sequence diagram is an interaction diagram that shows how process operates with one another and in what order, it is a construct of a message sequence chat, it also shows object interaction arranged in time sequence. The sequence diagram for this system is shown in Fig 3.
Database Design: Is a process of producing a detailed data model of a data base. This data model contains all needed logical and physical design choices and physical storage parameters needed to generate a design in a data definition language which can then be used to create a database. The database design for this system is shown in Fig 4

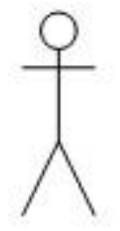

\section{Member}

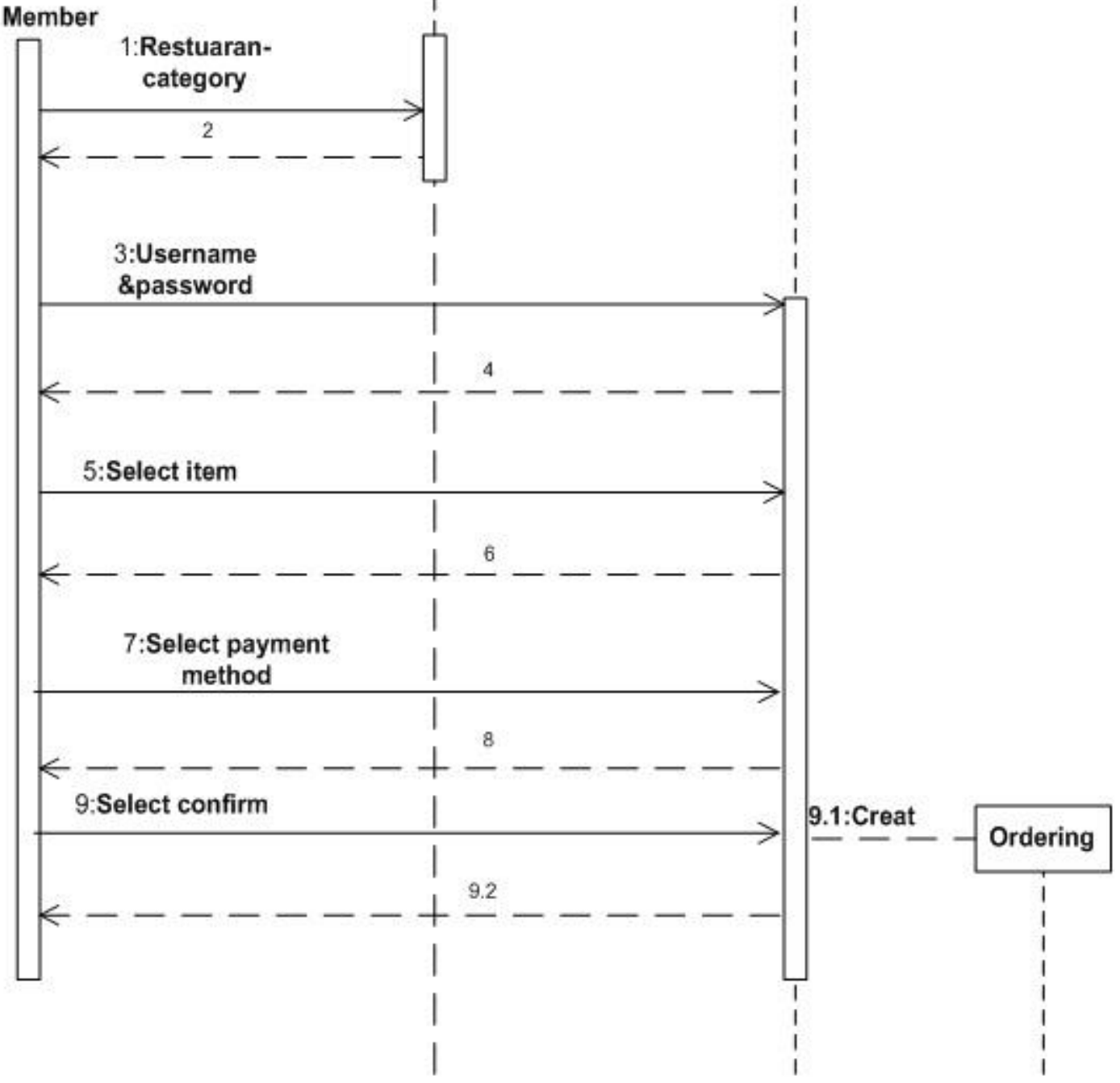

Fig 3: Sequence Diagram 


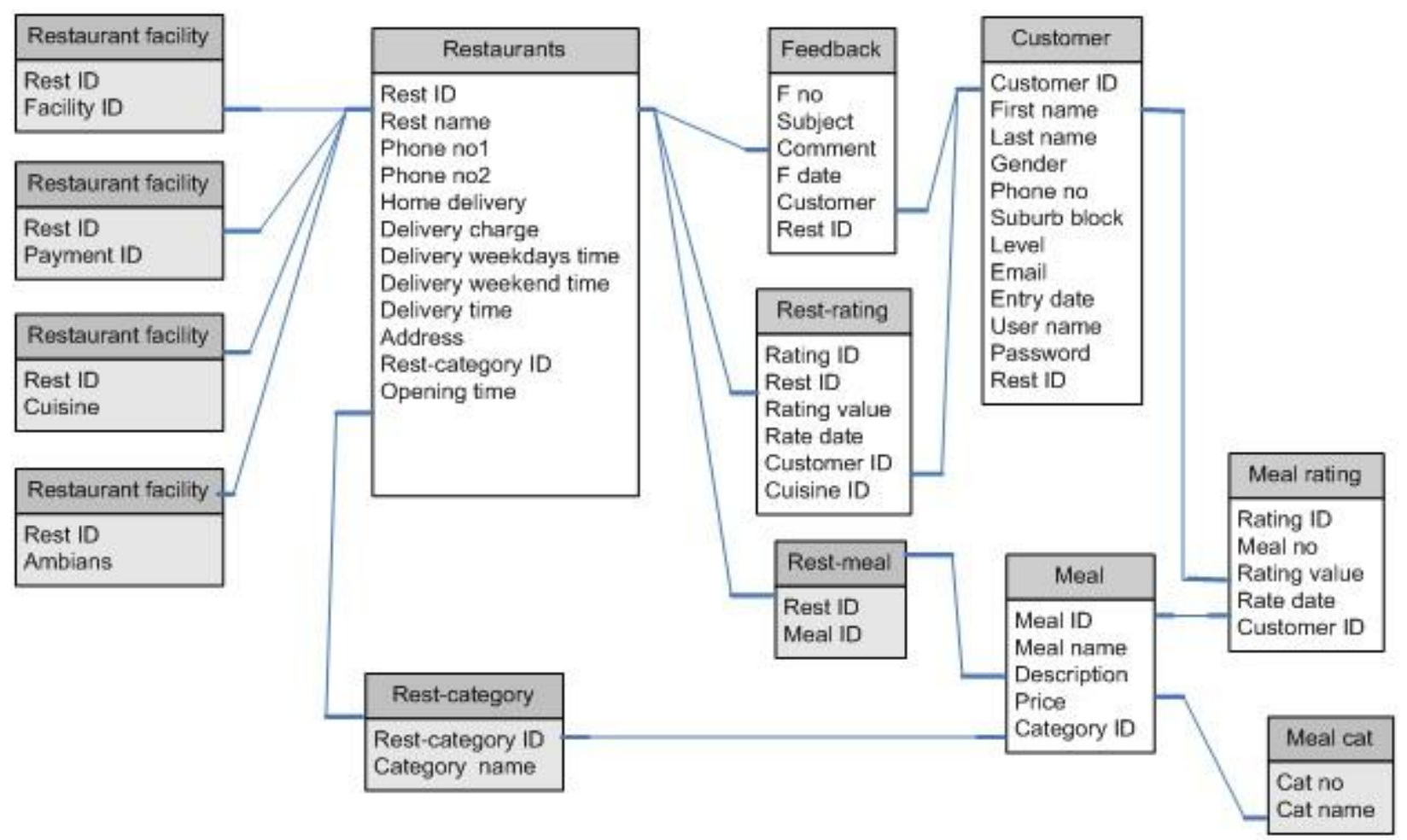

Fig 4: Database Design

\section{RESULTS}

The results from the system are given in Fig 6-13

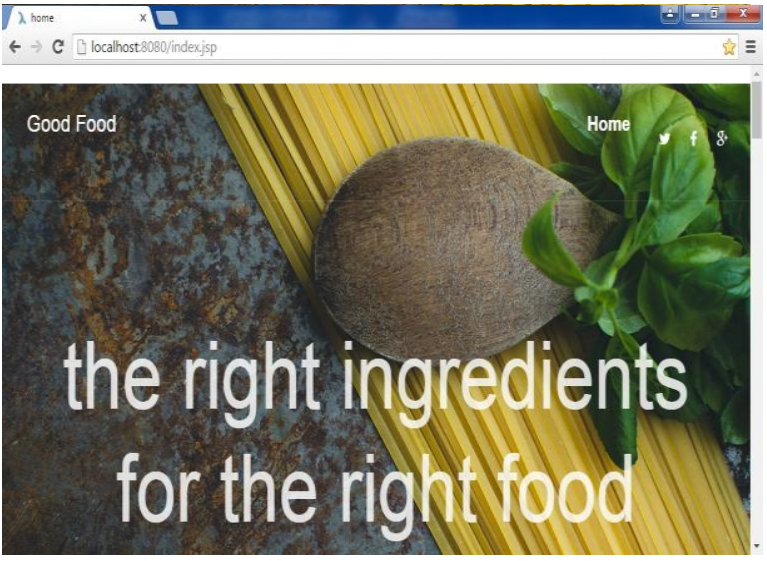

Fig 5: Home Page

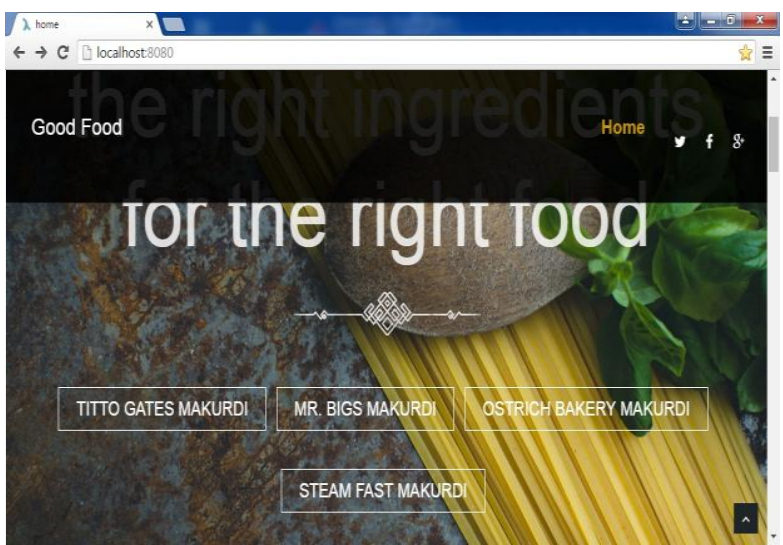

Fig 6: Restaurant Category 


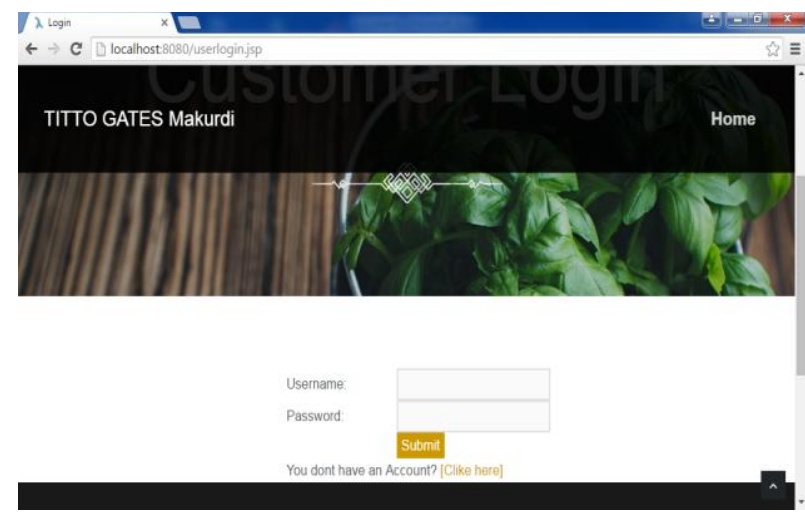

Fig 7: Authorization page

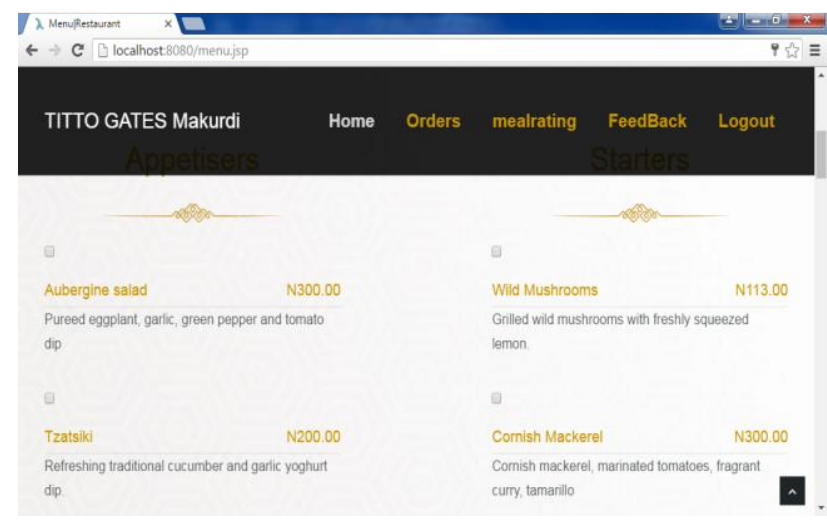

Fig 8: Menu page

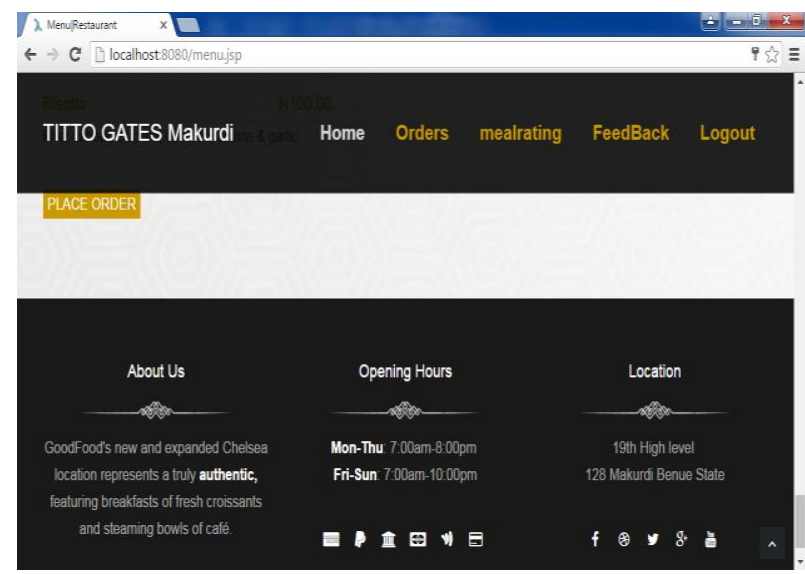

Fig 9: Ordering Tag

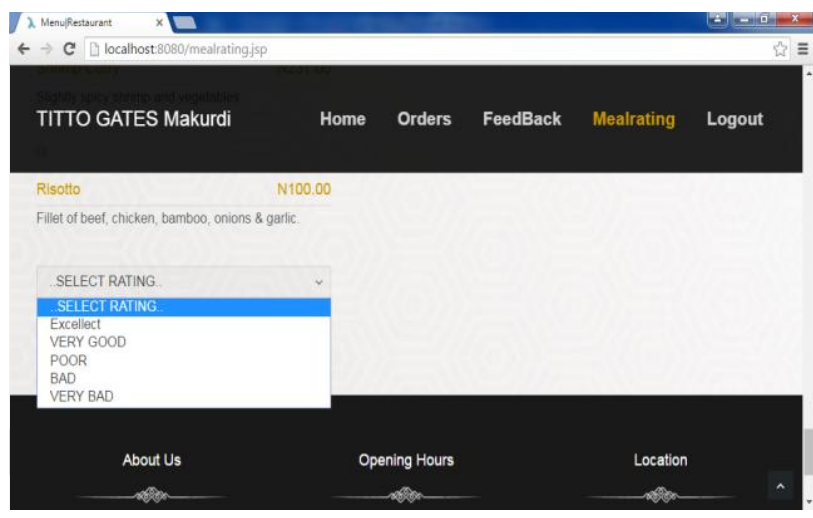

Fig 10: Meal rating

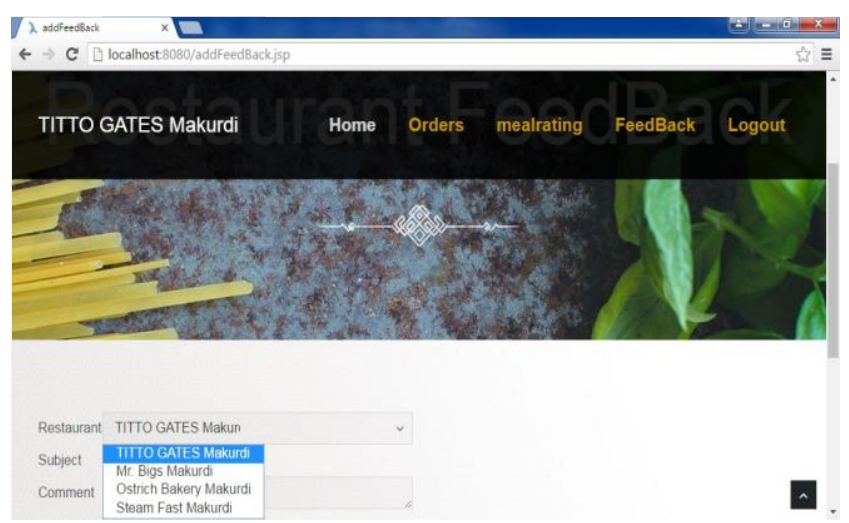

Fig 11: Restaurant Feedback

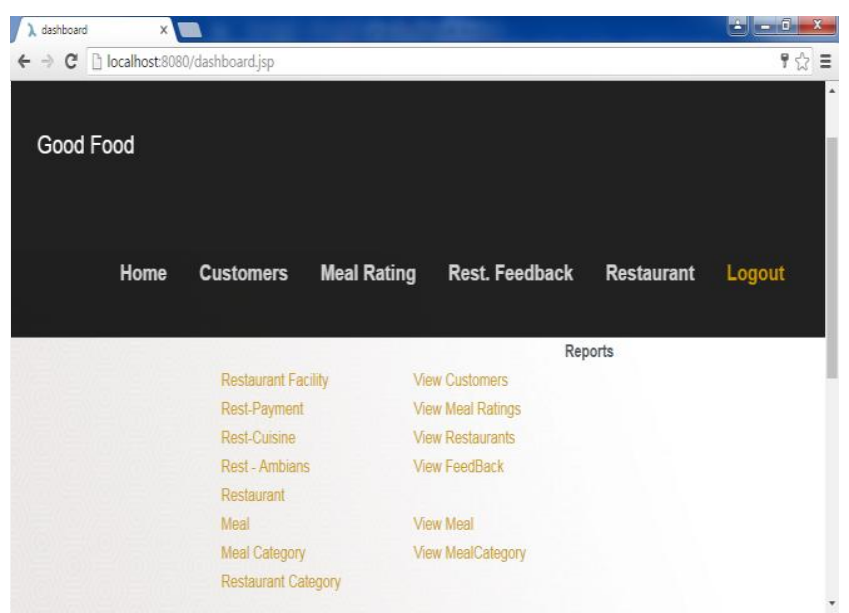

Fig 12: Manager views Report

\section{DISCUSSION}

This research work deals with the development of an online eatry management system with Titto Gate, Mr Biggs, Steam Fast, and Ostrich Bakery as case studies. These discussions coverse the following; Fig 6-13. Once the program is loaded the home page (Fig 6) is displayed. It houses the four different categories of restaurants. Fig 7 is the user authentication page where a user can enter his/her username credentials to access the system. Fig 8 is the menu page; it 
displays the different food items with description and prices. Fig 9 is where users make orders; after placing order, delivery is made (customer receives order). Fig 10 is the meal rating page. A customer is allowed to rate the kind of meal he/she took. Fig 12 is the feedback page. This page allows customers to give feedback on the restaurant services also the meal ordered for. Fig 13 are for manager's use; the manager views customers, meal ratings, feedbacks and adds new meals on the menu list.

The research has revealed that there is a great significant difference between the manual food ordering process and the automated computerized food ordering system. In the manual food ordering process, sales go unrecorded; staffs spend too much time correcting mistakes instead of attending to customers, lack of tally in inventory and discrepancies towards customers. The online automated system has eliminated most of the lapses faced in the manual system. This system minimized repetitive work done by the system administrator and staff as it is very common in the manual system; minimized the level of crowdedness at the eatry premises, thereby maintaining steady patronage; increased quality of service and customer satisfaction; make dinning a social tool; ensured accountability and error free handling of customer information and lots more.

\section{CONCLUSION}

This research has developed an online eatry management system that focused on ordering, reservation and delivery of food items from four eatries around Makurdi metropolis. Evidently, there exist a significant difference between the Manual food ordering process and the automated system. The automated system performed significantly and efficiently over the manual food ordering system, maximizing profit, less cost on inventory and accountability. This research work is targeted at meeting global standard in the eatry/restaurant industry within the confines of the mentioned eatries in this research work, to improve customers dining experience.

\section{REFERENCES}

[1] Dhore, V.B., Thakar, S., Kularni, P. and Thorate, R. 2014. Digital Table Booking and Food Ordering System Using Android Application. Internal Journal of Emerging Engineering Research and Technology, 2(7).

[2] Brandau. M. 2009. Restaurants Reap the Rewards of Loyalty Initiatives. Nations Restaurant News, 22: 1-3.

[3] Chavan, V., Jadhav, P., Korade. D. and Teli. P. 2015. Implementing Customizable Online Food Ordering System Using Web Based Application. International Journal of innovative science, Engineering \& technology, 2:4.
[4] Samson. M. 2004. Revved and Ready Restaurant Hospitality, 88(2), 41-49.

[5] Piccoli. G. 2008. Information Technology in Hotel Management: A Framework for Evaluating the Sustainability of it Dependent Eompetitive Advantage. Cornell Hospitality Quarterly, 49(3): 282.

[6] Graver. M. 2002. Using Data Mining for Customer Satisfaction Research.

[7] Oparanma, O., Hamilton, D.I. and Seth, J.A. 2009. Strategies for Managing Hospitality in a Turbulent Environment: Nigerian Experience. International Journal of Management and Innovation, 1(1): 24-37.

[8] Harrison. J. 2003. Strategic Analysis for the Hospitality Industry. Cornell Hotel and Restaurant Administration Quarterly, 2:139-152.

[9] Harrison, J. and John, S.T. 2008. Foundations in Strategic Management (4thed., rev).

[10] Piccoli, G. Spalding, B.R. and Ives, B. 2001. The Customer-service Life Cycle: A Framework for Improving Customer Service through Information.

[11] Luebke, P. 2010. Social media 101 for Independent Operator's Restaurant start up and Growth, 17-23.

[12] Magnini, V., Honeycutt, E. and Hodge, K. (2003). Data mining for Hotel Firms: Use and Limitations. Journal, 37(6): 1649-1665.

[13] Jin-zhao.W. and Jing, W. 2009. Issues, Challenges and Trends that Facing Hospitality Industry. Journal of Applied Business and Economics, 12(1): 20-79.

[14] Ross. J. R., 2006. Online Reservation Technology Gains Ground. Nations Restaurant News, 40(26): 68.

[15] Siguaw, J.A. and Enz, C.A. 1999. Best Practices in Information Technology.

[16] Bojanic, D. C and Rosen, I. D. 1994. Measuring Service Quality in Qestaurants: An Application of the Servqual Instrument. Hospitality Research Journal, 1: 3-14.

[17] Bhargave, A., Jadhav, N., Dhome, N. and Sarka, S. 2014. Design and Implementation of Digital Dining In Restaurant Using Android. International of Advance Research in Computer Science and Management Studies, 3(4).

[18] Ansell. D. and Dyer. C. 1999. A Framework for Restaurant Information Technology.

[19] Irvine, W. and Anderson, A. 2008. ICT (Information CommunicationTechnology). 